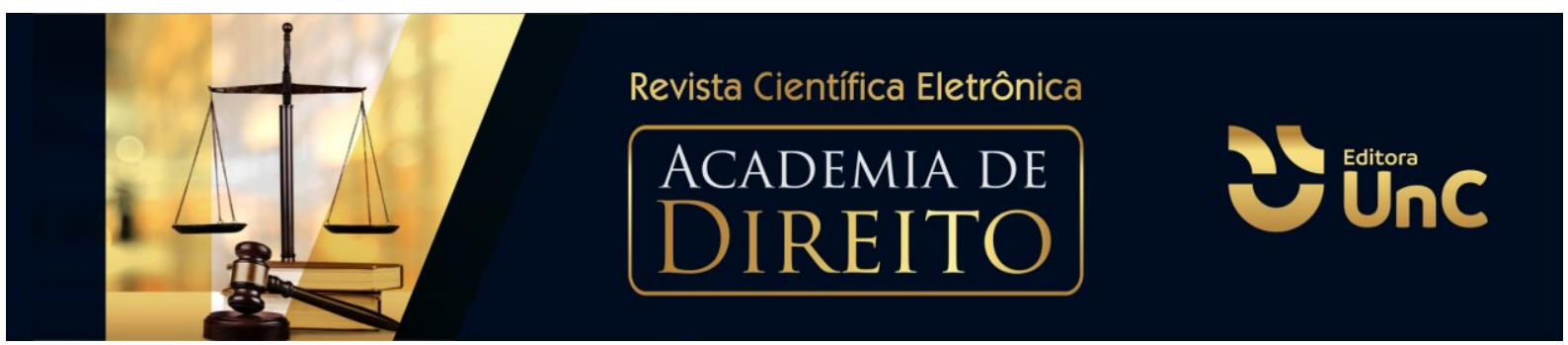

\title{
O DIREITO PENAL DO INIMIGO NO ORDENAMENTO JURÍDICO BRASILEIRO
}

Silvana Gentara ${ }^{1}$

Thiago Antonio Nascimento Monteiro Diniz ${ }^{2}$

\begin{abstract}
RESUMO
O presente trabalho visa discorrer sobre a tese idealizada por Günther Jakobs, criador do Direito Penal do Inimigo, objetivando responder a seguinte indagação jurídico-social: Existem fragmentos do Direito Penal do Inimigo no Ordenamento Jurídico Brasileiro? Considerando os aspectos idealizados por Jakobs, conclui-se que sua teoria é incompatível com um Estado de Direito, em razão da sua estrutura repressiva e, principalmente, pela supressão dos direitos e garantias, atingindo de maneira considerável a dignidade do ser humano. Através do método de abordagem qualitativo, utilizando técnicas bibliográficas e documentais, constatou-se a existência de dispositivos normativos que sofreram influências da teoria idealizada por Jakobs. Dessa forma, conclusivamente, a resposta foi sim. Embora o Ordenamento Jurídico Pátrio tenha como estigma a Carta Constitucional de 1988, repleta de garantias e princípios, mesmo incompatível com as ideias de Jakobs, existem influências desta teoria aplicadas no Brasil.
\end{abstract}

Palavras-Chave: Direito Penal do Inimigo. Garantias. Ordenamento Jurídico Brasileiro.

\section{CRIMINAL LAW OF THE ENEMY IN BRAZILIAN LEGAL ORDER}

\begin{abstract}
This paper aims to discuss the thesis developed by Günther Jakobs, creator of the Enemy's Criminal Law, aiming to answer the following legal-social question: Are there fragments of the Enemy's Criminal Law in the Brazilian Legal System? Considering the aspects idealized by Jakobs, it is concluded that his theory is incompatible with a rule of law, due to its repressive structure and, mainly, by the suppression of rights and guarantees, considerably affecting the dignity of the human

\footnotetext{
${ }^{1}$ Acadêmica de Direito da Universidade do Contestado (UnC). Campus Mafra. Santa Catarina. Brasil. E-mail: silvana gtra@hotmail.com

${ }^{2}$ Mestre em Direitos Fundamentais e Democracia, pelas Faculdades Integradas do Brasil (UNIBRASIL). MBA em Direito pela Fundação Getúlio Vargas (FGV-RIO). Graduado em Direito pela Faculdade de Direito de Curitiba (FDC). Professor de Direito da FAE - Centro Universitário. Professor de Direito Constitucional e Direito Administrativo na Universidade do Contestado (UnCMafra). Advogado. Curitiba. Paraná. Brasil. E-mail: thiagomonteirodiniz@gmail.com
} 
being. Through the qualitative approach method, using bibliographic and documentary techniques, it was verified the existence of normative devices that were influenced by the theory idealized by Jakobs. So, conclusively, the answer was yes. Although the Patio Juridical Order has as its stigma the 1988 Constitutional Charter, full of guarantees and principles, even incompatible with Jakobs' ideas, there are influences of this theory applied in Brazil.

Keywords: Enemy's Criminal Law. Guarantees. Brazilian legal system.

\section{INTRODUÇÃO}

O presente artigo tem por escopo discorrer, de maneira objetiva, sobre o Direito Penal do Inimigo, bem como analisar a existência de fragmentos desta teoria no ordenamento jurídico brasileiro.

A Teoria idealizada por Günther Jakobs, doutrinador alemão, originou-se da teoria dos sistemas de Luhmann. É adepta do funcionalismo sistêmico, também conhecido como funcionalismo radical. Essa teoria considera o Direito Penal um instrumento para assegurar a eficácia do sistema social e normativo.

O Direito Penal baseado no funcionalismo radical tem como função a estabilização da sociedade e individualização do crime como um distúrbio social. Assim, os atos contrários as normas são considerados como danosos socialmente, e não como um fato que violaria um bem jurídico. Desse modo, o fato criminoso é a frustração da expectativa normativa, e a pena seria a resposta dada pelo ordenamento para confirmar a vigência da norma violada.

Nesse sentido, existiram dois direitos penais: O Direito Penal do Cidadão e o Direito Penal do Inimigo. O Direito Penal do Cidadão seria a regra aplicada à pessoa que cometeu um crime, mas que demonstra garantias de obediência ao sistema normativo. Essa pessoa não deve ser vista pelo Estado como um delinquente persistente. Em contrapartida, o Direito Penal do Inimigo seria aplicado aos indivíduos que colocam em risco a existência do Estado, ou seja, os indivíduos que vivem em conflito continuo com o ordenamento jurídico. Por esse ângulo, o inimigo seria alguém que não oferece comportamento apto para viver em sociedade, sendo considerado perigoso.

A grande discussão que abrange a teoria de Jakobs, é de que o Direito Penal do Inimigo não seria compatível com um Estado de Direito, até porque é impossível 
fazer uma distinção entre quem seria o cidadão e o inimigo do Estado, haja vista que não caberia ao Estado distinguir esta condição da pessoa, o que já é uma qualidade inerente ao próprio ser humano.

Assim, não seria possível identificar quem seria o real destinatário do Direito Penal do Inimigo, o que poderia afetar não só as garantias do inimigo, mas de todos os cidadãos. Consequência desse comportamento, seria a geração de um Estado Absoluto, e não de um Estado de Direito. Nessa perspectiva, a aplicação do Direito Penal do Inimigo é contrária ao princípio da igualdade, uma vez que permite tratamento diferenciado, representa o enfraquecimento dos direitos fundamentais.

A tese idealizada por Jakobs é duramente criticada pela doutrina majoritária, em razão de seus postulados polêmicos. A legitimidade desse sistema jurídico é questionada, uma vez que a sua aplicação pode representar ofensa aos preceitos estabelecidos pela Constituição Federal, além da sua questionável efetividade para alcançar a redução da ocorrência de crimes e o alcance de uma sociedade pacífica.

Sendo assim, a tese de Jakobs não deveria encontrar respaldo na ordem jurídica brasileira, contudo, a possibilidade da existência de resquícios dessa teoria deve ser investigada, uma vez que a sua aplicação pode representar a supressão de princípios e fundamentos constitucionais.

Portanto, considerando sob o ponto de vista constitucional, os princípios fundamentais dispostos na Constituição Federal de 1988, especialmente o disposto no art. $1^{\circ}$, III e no art. $5^{\circ}$, caput, inciso $X$, conclui-se que, a aplicação da teoria de Jakobs caminha em sentido contrário à missão constitucional e, em uma possível aplicação, o Estado violaria preceitos estabelecidos na própria carta magna.

Contudo, mesmo com todas as garantias que o ordenamento jurídico brasileiro oferece, será forçoso concluir que não existe a aplicação de um direito penal do inimigo disfarçado ou implícito. Assim, o presente trabalho visa verificar a existência de fragmentos da teoria do doutrinador alemão Günther Jakobs no sistema normativo brasileiro.

Por todo o exposto, é possível assim formular a seguinte hipótese de pesquisa: a existência de fragmentos do Direito Penal do inimigo no ordenamento jurídico brasileiro representa ofensa ao Estado Democrático de Direito.

Sendo assim, o objetivo é trazer as principais características do Direito Penal do Inimigo, analisar os possíveis fragmentos da teoria de Jakobs no ordenamento 
pátrio, além das críticas que demonstram a sua incompatibilidade com o Estado de Direito.

Toda a pesquisa será realizada com base no método de raciocínio hipotético dedutivo qualitativo, a fim de realizar um exame rigoroso sobre o direito penal do inimigo e a sua aplicação no ordenamento jurídico brasileiro, utilizando a técnica de pesquisa bibliográfica e documental.

O tema abordado é de fundamental importância para o sistema jurídico brasileiro, em razão de que, ao ser aplicado, pode importar na violação às garantias constitucionais e aos direitos fundamentais, além da ofensa ao princípio da dignidade da pessoa humana.

Com este breve estudo, pretende-se investigar a existência da teoria de Jakobs no sistema normativo brasileiro, buscando fragmentos que podem levar a supressão de várias garantias processuais e materiais, causando assim uma desigualdade entre os cidadãos.

\section{O DIREITO PENAL DO INIMIGO}

\subsection{CONCEITO E CARACTERÍSTICAS DO DIREITO PENAL DO INIMIGO}

O direito penal do inimigo é um Direito Penal de exceção, cuja principal fundamentação teórica seria a distinção entre os cidadãos e os não-cidadãos, conduzindo à distinção entre dois polos de regulação normativa, um aplicado ao cidadão e outro ao inimigo (PRADO, 2009).

Em suma, é a uma tese jurídica segundo, a qual, determinados indivíduos, que agem de maneira contrária ao ordenamento jurídico, colocando em risco o meio social, além de sua recusa constante ao sistema normativo vigente, deve ser tratado como inimigos da sociedade. Seriam objetos do poder estatal, não mais considerados titulares de direitos (JAKOBS, 2007, p. 45).

Assim, o Direito Penal do Inimigo trata do indivíduo que, deliberadamente, deixou o vínculo social, abandonando o seu status de pessoa e a titularidade de direitos e deveres, passando a ser reconhecido como uma fonte de perigo que precisa ser eliminada, a fim de que a estrutura normativa e a própria sociedade fiquem protegidos (COSTA, 2012, p. 8-9). 
Sobre esse pondo, Jakobs (2008, p. 17) salienta que:

[...] quem não pode oferecer segurança cognitiva suficiente de que se comportará como pessoa não só não pode esperar ainda ser tratado como pessoa, como tampouco o Estado estará autorizado a tratá-lo ainda como pessoa, pois, de outro modo, estaria lesando o direito das outras pessoas à segurança.

Luiz Regis Prado (2009) afirma que a tese de Jakobs "consiste na própria separação entre pessoas e não-pessoas". Essa tese faz a distinção entre quem seria considerado inimigo e quem seria o criminoso comum. Os criminosos comuns serão e devem ser punidos, mas os inimigos devem ser abatidos; no que se refere a estes, não se trata de retribuição pelo ato cometido, conforme o modelo do direito penal clássico, trata-se de defesa (VELO, 2010, p. 8).

Nesta circunstância, a redução das garantias e princípios aplicados aos inimigos justifica-se, uma vez que são sujeitos não confiáveis, portanto, incapazes de serem combatidos com o direito penal clássico (VELO, 2010, p. 9).

O penalista alemão considera impossível combater o inimigo com os meios aplicados em um Estado de Direito, já que um Direito Penal geral trataria o cidadão e o inimigo como pessoas. Razão pela qual o Direito Penal do Inimigo seria a alternativa perfeita para aniquilar o inimigo de modo eficiente, sem que isso cause a ruína do direito (COSTA, 2012, p. 9).

$O$ direito penal do inimigo possui três elementos caracterizadores: o primeiro elemento é o de que a perspectiva do Direito penal do inimigo possui uma prospectiva, ou seja, o ponto de referência seriam os fatos futuros, deste modo, existiria um adiantamento da punibilidade, diferente do direito habitual, que pune fatos pretéritos. Em segundo lugar, as penas aplicadas seriam desproporcionalmente mais significativas. Em terceiro lugar, as garantias processuais podem ser relativizadas ou, até mesmo, não aplicadas (JAKOBS, 2007, p. 67).

Uma das características mais marcantes do Direito Penal do inimigo é o combate a perigosos, representando, assim, em muitos casos, uma antecipação da punibilidade, ocasião em que o "inimigo" seria interceptado em um estado inicial, considerando a periculosidade que representa para o meio social. Sendo assim, o inimigo já não é mais considerado homem, o centro de todo o Direito, mas apenas 
um sistema puramente sócionormativo (PRADO, 2009).

A teoria idealizada por Jakobs também possui outras características, quais sejam: (a) o inimigo será punido com medida de segurança, não com a aplicação da pena; (b) será punido de acordo com a periculosidade que representa para a sociedade, não de acordo com a sua culpabilidade; (c) as medidas tomadas contra o inimigo levam em consideração atos futuros (o que ele representa de perigo futuro), não o que o indivíduo fez no passado; (d) é caracterizado por ser um Direito Penal prospectivo (visando o futuro); (e) o inimigo perde seu status de pessoa, sendo considerado objeto de coação e não um sujeito de direito; (f) o cidadão, mesmo cometendo crimes, mantém seu status de pessoa; (g) a principal função do Direito Penal do Inimigo é o combate a perigosos; o Direito Penal do Cidadão visa manter a vigência da norma; (h) o Direito Penal do Inimigo deve buscar antecipar a tutela penal, objetivando alcançar os atos preparatórios (i) mesmo que a pena aplicada aos atos preparatórios seja desproporcional, ainda assim, justifica-se; (j) para que o Direito Penal possa ser aplicado ao cidadão, é necessário que ele exteriorize a conduta criminosa; em relação ao inimigo, este deve ser interceptado antes da ocorrência do fato, considerando a sua periculosidade (GOMES, 2005, p. 2).

Ademais, a pena aplicada ao inimigo possui, além do significado físico, representado pela reprimenda corporal, um significado simbólico. Quando o criminoso comete um delito, isso representa um comportamento contrário ao que foi estabelecido pela norma, uma agressão à sua eficácia. Dessa forma, a aplicação da pena é, simbolicamente, a contraproposta do Estado e da sociedade, demonstrando que a norma continua com a sua vigência intacta, que o crime cometido foi irrelevante para o fim de destruir o ordenamento jurídico. Quanto ao seu caráter físico, a pena impede que o criminoso, enquanto encarcerado, cometa novos crimes. Sua função é preventiva e não se dirige somente ao criminoso, mas também ao cidadão, indivíduo que é fiel ao ordenamento, servindo como reafirmadora da norma (GOMES; MOLINA; BIANCHINI, 2007, p. 296).

Para a doutrina tradicional, o bem jurídico é o interesse cultivado e valorado em determinada norma e comunidade. Quanto ao funcionalismo radical de Jakobs, o bem jurídico tutelado seria a norma e o objetivo da pena seria a de confirmar a vigência da norma que foi violada. Sendo assim, para que a norma seja socialmente válida, ela deverá, além de ser respeitada pela sociedade, sustada 
contrafaticamente, já que nos dois casos ela cumprirá a função de obedecer à segurança das expectativas (COSTA, 2012, p. 8).

Dessa maneira, o indivíduo que comete atos contrários à norma penal causaria uma ruptura da expectativa de comportamento esperado, razão pela qual a pena teria a finalidade de marginalizar o ato e confirmar contrafaticamente a validade da norma violada, gerando estabilidade das expectativas e do próprio sistema jurídico (COSTA, 2012, p. 8).

Como já mencionado, agindo em concordância com a tese do Direito Penal do Inimigo, o Estado poderá proceder de duas maneiras distintas contra o criminoso: pode vê-los como pessoas que delinquem ou como indivíduos que apresentam comportamento grave contra o Estado. Dessa maneira, existiria a aplicação de dois direitos: um empregado ao cidadão, que deve ser respeitado e contar com todas as garantias inerentes ao seu direito (penal e processual); o outro é o Direito Penal do inimigo, onde o indivíduo recebe tratamento rígido, sendo visto como uma fonte de perigo (JAKOBS, 2007, p. 42).

Antes de adentrar ao assunto, cabe mencionar que ambos os "Direitos Penais", o do cidadão e o aplicado ao inimigo, não podem ser vistos como dois campos completamente distintos isolados. São dois extremos de uma única esfera, aplicados em um único contexto jurídico-penal (JAKOBS, 2007, p. 21).

De acordo com o entendimento de Gomes, Molina e Bianchini (2007, p. 296) "o Direito penal do cidadão é um Direito Penal de todos; o Direito penal do inimigo é contra aqueles que atentem permanentemente contra o Estado: é coação física, até chegar à guerra".

Essa distinção também foi demarcada pelo próprio Jakobs (2008, prefácio), no prefácio de seu livro "Direito Penal do Inimigo", onde ele escreve:

São regras jurídico-penais que, como suas correlatas, as regras do Direito Penal do Cidadão, somente são concebíveis enquanto tipos ideias. O Direito Penal do Inimigo é essencialmente, violência silenciosa; o Direito Penal do Cidadão é, sobretudo, comunicação sobre a vigência da norma.

Portanto, o cidadão, apesar de ter violado o ordenamento através do cometimento de um delito, demonstra ao Estado que seu comportamento está submisso às normas jurídicas. O inimigo, em contraponto, não oferece garantias de 
submissão, demonstrando que sua violação e desrespeito à ordem imposta podem ser permanentes (GOMES; BIANCHINI; MOLINA; 2007, p. 296).

$\mathrm{O}$ tratamento diferenciado que o inimigo recebe, justifica-se pelo fato de que sequer são pessoas, afirmando que um indivíduo que não está apto a viver em uma sociedade civilizada e com regras, não pode desfrutar das benesses do conceito de pessoa. Dessa maneira, não são consideradas pessoas (JAKOBS, 2007, p. 34).

Assim, o aparato estatal, exerce um controle vigilante sobre a sociedade e, principalmente, sobre os indivíduos que podem ser considerados "ervas daninhas" da estrutura social (COSTA, 2012, p. 5).

Nessa tese, o conceito de pessoa é relativo e depende da construção social onde ela está integrada, consequentemente, não seria permanente, nem preponderante. Sendo assim, acredita que essa proposição é extremamente abstrata, pois o próprio comportamento do indivíduo é decisivo para que ele seja tratado como cidadão (JAKOBS, 2007, p. 78-79).

Sendo assim, a aplicação do Direito Penal do cidadão não comporta a aplicação de medidas extremas, sendo distinto do Direito Penal do Inimigo. O Direito penal aplicado ao cidadão, o qual mantém seu status de pessoa, sanciona os delitos de maneira casual, suas penas são voltadas para a contenção/correção de desvios provocados pelo cidadão, mas que não atingiram a soberania do ordenamento (MARTÍN, 2007).

O Direito Penal do Cidadão visa a punição de fatos criminoso, sendo essencialmente repressivo, por este motivo, se ocupa com condutas consumadas ou tentadas. De outro modo, o Direito Penal do inimigo pune a periculosidade do agente, sendo preventivo, antecipando a tutela penal para coibir atos preparatórios (QUEIROZ, 2008, p. 46).

As penas para o Direito Penal do Inimigo e o Direito Penal do Cidadão também teriam funções diferentes. Para o Direito Penal do Cidadão, ela seria contradição; quanto para o inimigo, a eliminação. Ambas seriam legítimas. (JAKOBS, 2005, p. 49).

O inimigo, diante da sua inconfiabilidade e complexidade, não seria compatível com o sistema normativo garantista, embora em certo momento histórico, tenha sido criado para isso (VELO, 2010, p. 8).

Feitas essas considerações, é importante realizar à análise de quem seria o 
inimigo na tese de Jakobs.

Prima facie, é importante instar que nem todo delinquente deve ser visto como um inimigo, em outras palavras, nem todo autor de um crime perde o seu status de pessoa (JAKOBS, 2007, p. 43).

Como já mencionado anteriormente, o cidadão, mesmo agindo de maneira errônea, ainda que isso ocorra mais de uma vez, desde que apresente garantias de submissão ao ordenamento, não deverá ser visto como um inimigo. Porém, o indivíduo que não permite ser submetido às regras de um estado de cidadania não pode participar dos benefícios que o status de pessoa propõe (JAKOBS, 2007, p. 45).

Essa noção apresentada por Jakobs, demonstra que o inimigo é o indivíduo que se apresenta de maneira contrafática ao ordenamento, aquele indivíduo que, a todo modo, nega a existência de normas que regulamentam o comportamento social e não demonstram garantias de que voltarão a prestar fidelidade às normas. Nesses casos, os indivíduos não devem ser vistos como pessoa, mas como inimigo, em função da periculosidade que apresenta.

Nesse esteio, Jakobs (2003, p. 49-50) explica que:

\begin{abstract}
Quem por princípio se conduz de modo desviado, não oferece garantia de um comportamento pessoal. Por isso, não pode ser tratado como cidadão, mas deve ser combatido como inimigo. Esta guerra tem lugar com um legítimo direito dos cidadãos, em seu direito à segurança; mas diferentemente da pena, não é o Direito também a respeito daquele que é apenado; ao contrário, o inimigo é excluído.
\end{abstract}

Sendo assim, pessoa seria quem presta "garantia cognitiva suficiente de um comportamento pessoal”, já que, sem essa mínima garantia, a sociedade constituída juridicamente não funciona (JAKOBS, 2005, p. 45).

O indivíduo, através de um pacto social, se obrigou a prestar obediência absoluta às leis que regem o poder soberano. A hipótese de recusa a essa obediência implica na renúncia de todo o sistema e isso é visto como traição (HOBBES, 2002, p. 231).

Quem não se submete à norma, tem uma guerra travada contra si, onde o vencedor é quem dita as regras ao vencido. Dessa maneira, o inimigo é quem abandona de maneira duradoura, não somente de maneira incidental (VALE, 2011, 
p. 2).

O inimigo é um opositor irreconciliável, ou seja, é o indivíduo que apresenta uma rejeição duradoura às regras de Direito. Aquele indivíduo que desenvolve a sua vida (profissão, vida pessoal, vida econômica, entre outras áreas) às margens das normas e, além de refutar a legitimidade do ordenamento jurídico, busca a sua destruição (PRADO, 2009).

O inimigo frustra as expectativas sociais quando, por vontade própria, afastase da estrutura normativa. Em contrapartida, o cidadão é pessoa titular de direitos e deveres, comportando-se segundo expectativas sociais (COSTA, 2012, p. 8).

Segundo se depreende dos descritos de Jakobs, os inimigos podem ser criminosos econômicos, indivíduos que cometem crimes sexuais, quem participa de organizações criminosas, terroristas, pessoas que tenham envolvimento com o tráfico de drogas, entre outros indivíduos perigosos (GOMES, 2005, p. 1). Para Jakobs, o que ocorreu no fatídico dia 11 de setembro de 2001 é uma manifestação clara de um ato praticado pelo inimigo (GOMES; MOLINA; BIANCHINI, 2007, p. 295).

O indivíduo que se mostra opositor assíduo do ordenamento jurídico não deve ser visto como alguém que cometeu um erro, já que o objetivo dele é justamente causar a ruptura do ordenamento, conduta típica de um terrorista que declara guerra ao Estado, razão pela qual será combatido com um direito de guerra (JAKOBS; MELIÁ; 2007, p. 36).

Doutrinadores asseguram que o criminoso comum é aquele que comete crimes habituais (roubos, furtos, assassinatos e outros do cotidiano). Por outro lado, o inimigo comete atos que atentam contra a paz do Estado, como terrorismo, genocídios e pelas suas práticas reiteradas, compromete a própria existência do Estado (SILVA; OLIVEIRA; FOLLONE, 2011).

O fato do indivíduo cometer crimes que são considerados perigosos para a segurança do ordenamento, faz com que ele perca a sua cidadania, razão pela qual não seria digno de invocar os direitos que um cidadão comum teria. Dessa forma, até a aplicação da pena de morte seria possível, a fim de que esse sujeito não cometa mais qualquer crime (SILVA; OLIVEIRA; FOLLONE, 2011).

Diante do afastamento deliberado das expectativas, poderia ser justificada a supressão/diminuição das proteções penais e processuais penais (COSTA, 2012, p. 
8). O irreconciliável precisa receber uma coação, ainda que desproporcional ao ato cometido, a fim de que seja impedido de destruir o ordenamento jurídico (JESUS, 2019).

$\mathrm{Na}$ concepção de Jakobs (2009, p. 28), a justificativa de que todas devem ser vistos como pessoas, é mera argumentação, não constituindo, de fato, uma sociedade realmente operante e eficiente. Sendo assim, para ser considerado uma pessoa, sujeito de direitos, o cidadão deve conquistar tal feito, para tanto, deve começar respeitando as premissas impostas pelo Estado, já que o conceito de pessoa não deve ser confundido com o de ser humano, esse é derivado da natureza; àquele, depende do seu comportamento e do meio onde o indivíduo está inserido.

A legitimidade para realizar a exclusão do status de pessoa, na acepção do penalista alemão, é daquele que tem o direito de estabelecer o que é norma. (JAKOBS, 2005, p. 36).

No entanto, o conceito de inimigo é bastante criticado, pois, existe uma ausência de informações que possibilitem a real limitação de quem seria o inimigo e quem seria o cidadão, consequência disso seria a geração de insegurança, uma vez que ninguém estaria desobstruído de ser imputado como inimigo (VÁSQUEZ, 2006).

\subsection{FRAGMENTOS DO DIREITO PENAL DO INIMIGO NO ORDENAMENTO JURÍDICO BRASILEIRO}

Nas últimas décadas, o crescimento da violência no Brasil, principalmente nos grandes centros urbanos, é evidente. Os atos criminosos que geram grande repercussão, seja pela crueldade, futilidade, ou até mesmo os crimes não-violentos, chamados crimes corporativos (ou cometidos por colarinhos-brancos), motivam o clamor popular, reclamando que o Estado Ihes proporcione segurança diante dos criminosos (RAZABONI JÚNIOR, 2017, p. 37).

Esse quadro de insegurança e medo social desencadeia o anseio do Estado pela busca de uma segurança pública implacável, ocasião onde se busca, através da severidade das normas, a punição dos desviantes. Sendo assim, o Direito Penal do Inimigo poderia ser visto como uma alternativa válida, embora contrário ao Estado de Direito (RAZABONI JÚNIOR, 2017, p. 38). 
As construções legislativas recentes no Brasil já adotariam alguns mandamentos inerentes ao Direito Penal do Inimigo. Exemplo disso, seria a Lei $n^{\circ}$ 9.034, de 3 de maio de 1995, que foi instituída para tratar do combate as práticas cometidas por organizações criminosas (MASSON, 2006, p. 148).

Neste dispositivo, permite-se o controle monitoramento da quadrilha, a fim de que a busca por provas seja realizada no momento mais oportuno. Com isso, o acesso a informações fiscais, bancárias, telefônicas, a infiltração de agentes de polícia, entre outros aspectos, se dará mediante autorização judicial (RAZABONI JÚNIOR, 2017, p. 47).

A Lei dos Crimes Hediondos (Lei $n^{\circ}$ 8.072/1990), onde constava a proibição de liberdade provisória (atualmente excluída pela Lei $n^{\circ} 11.464 / 2007$ ), além da vedação de indulto, com a determinação do cumprimento integral da pena em regime fechado, também pode ser citada. Atualmente, tal dispositivo, segundo o Supremo Tribunal Federal, no julgamento do HC 82.959-7, foi declarado inconstitucional, permitindo o apelo em liberdade, mediante decisão motivada, em caso de sentença condenatória (ALENCAR, 2010, p. 8).

A Lei $n^{\circ} 10.792 / 2003$, que instituiu o Regime Disciplinar Diferenciado, onde contém, dentre outras medidas restritivas, a determinação de que o preso fique em cela individual, com direito a banho de sol de duas horas diárias e visitas semanais de duas horas, sanções aplicadas aos detentos que cometem crimes hediondos ou faltas graves dentro do estabelecimento prisional (RAZABONI JÚNIOR, 2017, p. 50).

Cotejando o texto constitucional, os dispositivos contidos na Lei $\mathrm{n}^{\circ}$ 10.792/2003 são inconstitucionais, uma vez que a Carta Magna dispões que não poderão ser instituídas penas cruéis (art. $5^{\circ}, \mathrm{XLVII}, \mathrm{CF} / 88$ ), garantindo-se ao presidiário o respeito a integridade física e moral, além de não serem submetidos a tratamento desumano ou degradante (ALENCAR, 2010, p. 7).

Assim, a Lei $n^{\circ} 10.792 / 2003$ pode ser tida como um claro exemplo de Direito Penal do Inimigo, já que a submissão do detento a um esquema de isolamento completo, não tem relação com o crime cometido por ele, nada tendo com o direito penal do fato, identificando-se mais com o Direito Penal do Autor (BUSATO, 2004, p. $3 / 4)$.

Pode-se mencionar também a Lei do Abate (Lei N 9.614/98), a qual propicia a derrubada das aeronaves consideradas perigosas dentro do território nacional. Tal 
lei afronta aos direitos fundamentais constitucionais, especificamente no que se refere ao direito à vida, à liberdade, além do devido processo legal, ampla defesa e o contraditório (ALENCAR, 2010, p. 8).

O dispositivo supramencionado permite a destruição de aeronaves que representam perigo a segurança nacional ou suspeitas de transporte de tráfico ilícito de drogas, induzindo a execução extrajudicial, permitindo a condenação do agente a pena de morte, sem qualquer processo legal (ALENCAR, 2010, p. 8).

Outro instituto que contem mandamentos do Direito Penal do Inimigo e pode ser mencionado é a delação premiada, contido no art. $8^{\circ}$, parágrafo único, da Lei 8.072/90, no art. $6^{\circ}$ da Lei $n^{\circ} 9.034 / 95$ e art. 159 , $\S 4^{\circ}$, do Código Penal. A delação premiada é destinada ao inimigo que se arrepende e quer colaborar com o Estado (MASSON, 2006, p. 148).

Assim, verifica-se que existem fragmentos, ainda que mitigados, no ordenamento jurídico brasileiro (GOMES, 2005, p. 3). O fato é que o Direito Penal do Inimigo está destinado a crescer, ainda que seja ilegítimo.

\subsection{CRÍTICAS AO DIREITO PENAL DO INIMIGO}

Apesar dos adeptos, o Direito Penal do inimigo coleciona muitas críticas no aspecto nacional e internacional, principalmente por sua feição análoga ao Direito Penal do Autor (MORAES, 2011, p. 125).

O Direito Penal do Autor teve seu auge durante o período nazista e, assemelhando-se ao Direito Penal do Autor, o Direito Penal do Inimigo causa a "demonização" de determinados criminosos (GOMES, 2005, p. 3).

À vista, salienta-se que, tanto o Direito Penal do Inimigo, quanto o Direito Penal do Autor, caracterizam-se por não se direcionarem ao fato criminoso, mas ao seu autor, ou seja, na perspectiva de que o agente cometa um crime. Dessa forma, busca-se a antecipação da pena como uma forma de assegurar e impedir o cometimento de crimes, baseando-se na neutralização do autor (GOMES, 2005, p. 3).

O que está em ênfase no Direito Penal do inimigo não é a culpabilidade do agente, sim, a sua periculosidade, desse modo, não há espaço para proporcionalidade na aplicação de penas (GOMES, 2005, p. 3). 
Além disso, o Direito Penal do Inimigo representa a perda de garantias penais e processuais, exemplo disso seria a supressão do princípio do devido processo legal, já que para o inimigo é aplicado um procedimento de guerra, contudo, essa lógica de intolerância é incompatível com um estado de direito que presa pelas garantias penais e processuais penais (GOMES, 2005, p. 3).

A divisão entre cidadão e inimigos também gera diversas críticas, já que, em um Estado de Direito, regido por princípios como da legalidade e da igualdade, não há como separar os seres humanos em categorias de "cidadãos" e "inimigos", retirando destes, garantias fundamentais. De outro modo, o Estado só favoreceria a intolerância e o abuso de direito (CALLEGARI; DUTRA, 2007, p. 9).

Como já mencionado, o inimigo eleito não é considerado pessoa, pois ele não oferece um grau mínimo de comprometimento com o ordenamento jurídico. Sendo assim, a supressão de garantias e princípios têm o objetivo de, além de segregá-lo, ser enfático no combate a determinados crimes, como terrorismo e tráfico de drogas, por exemplo. Dessa forma, busca a extinção de certo grupo de indivíduos, visando, mais uma vez, o autor e não o fato (GOMES, 2005, p. 1).

Criticando a eleição de um inimigo, Zaffaroni (2007, p. 18) sustenta:

Na medida em que se trata um ser humano como algo meramente perigoso e, por conseguinte, necessitando de pura contenção, dele é retirado ou negado o seu caráter de pessoa, ainda que certos direitos (por exemplo, fazer testamento, contrair matrimônio, reconhecer filhos etc.) Ihe sejam reconhecidos. Não é a quantidade de direitos de que alguém é privado que Ihe anula a sua condição de pessoa, mas sim a própria razão em que essa privação de direitos se baseia, isto é, quando alguém é privado de algum direito apenas porque é considerado pura e simplesmente como um ente perigoso.

O inimigo não deve ser visto como um sujeito do processo, não podendo contar com os princípios aplicados ao procedimento penal. Como já mencionado, para ele, existe um procedimento próprio de guerra, e quem ganha a guerra é quem determina as normas aplicadas, cabendo ao Estado a imposição e a concreta submissão às leis (NUCCl, 2011, p. 87).

Destarte, verifica-se que ficaria a cargo do Estado definir quais condutas poderiam classificar o autor como um inimigo, uma vez que caberia a ele definir quais atitudes poderiam colocar em perigo a ordem jurídica. Por derradeiro, vale lembrar que cabe ao Estado também julgar esses crimes. Sobre esse ponto, escreve 
Zaffaroni (2007, p. 82):

Em outras palavras, a história do exercício real do poder punitivo demonstra que aqueles que exerceram o poder foram os que sempre individualizaram o inimigo, fazendo isso da forma que melhor conviesse ou fosse mais funcional - ou acreditaram que era conforme seus interesses em cada caso, e aplicaram esta etiqueta a quem os enfrentava ou incomodava, real, imaginária ou potencialmente.

O Estado pode até privar o criminoso de sua cidadania, mas jamais poderá privá-lo da sua condição de pessoa, como natural portador de direitos e deveres, inerentes a qualquer ser humano. Dessa forma, a incompatibilidade do direito penal do inimigo, pois não é possível a aplicação de um tratamento diferenciado, sem que isso implique em seu caráter de pessoa (ZAFFARONI, 2007, p. 19).

Nessa linha de pensamento, o penalista alemão abre brechas para a existência de um direito penal sem limites, onde seriam admitidas a criminalização de opiniões diferentes ou de manifestações extremistas, bem como a existência de penas desproporcionais (inclusive pena de morte) e a admissão de meios de provas ilícitos (como tortura) (CONDE, 2010, p. 3).

Além disso, essa despersonalização traz insegurança jurídica, pois "convém advertir que a priorização do valor segurança como certeza acerca da conduta futura de alguém, e mais ainda sua absolutização, acabaria na despersonalização de toda a sociedade" (ZAFFARONI, 2007, p. 20).

Nessa esteira, o Direito Penal do Inimigo pode ser visto como um fruto na junção do Direito Penal Simbólico com o Direito Penal Punitivista, já que sua aplicação exagerada da tutela penal, com a antecipação da punição e penas desproporcionais, não representa outra finalidade, senão atender a irá da população (GOMES, 2005, p. 3).

A compatibilização do Direito Penal do Inimigo com o atual sistema jurídico, político e social não é sensata, tampouco prudente, pois a criação de inimigos fora de um contexto bélico dá asas para que devaneios autoritários possam se concretizar. A ideia de inimigo, então, pode ser entendida como um elemento conceitual contraditório dentro do Estado Democrático de Direito porque arrasta consigo a semente de sua destruição (COSTA, 2012, p. 11).

Além disso, como já mencionado anteriormente, o inimigo não apresentaria 
segurança cognitiva suficiente. Mas o que seria essa segurança cognitiva? Em tese, seria um conceito totalmente subjetivo, abrindo parâmetro para várias interpretações. Em uma delas, pode ser vista como a capacidade do indivíduo de se comportar de acordo com ordenado na norma (CONDE, 2005, p. 35).

Ao analisar a teoria de Jakobs, nítido que seus aspectos confrontam diretamente $o$ ordenamento jurídico brasileiro, e a sua aplicação seria inconstitucional. Isso pode ser comprovado, uma vez que o Direito Penal do Inimigo implica na supressão de garantias penais e processuais, ferindo princípios como a ampla defesa e o contraditório (RAZABONI JÚNIOR, 2017, p. 48).

Ademais, ofende as garantias fundamentais e direitos previstos no artigo $5^{\circ}$ da Constituição Federal, além dos elencados como cláusulas pétreas, com previsão no artigo $60, \S^{\circ}$ da Carta Magna (RAZABONI JÚNIOR, 2017, p. 48).

\section{CONSIDERAÇÕES FINAIS}

O sistema jurídico brasileiro é conhecido como protetor e garantidor, contém princípios e direitos que são pilares da Carta Constitucional de 1988, além de representarem o caminho para a criação das demais normas pelos legisladores, visando assegurar tratamento digno e igualitário aos cidadãos.

Contudo, com base no contexto histórico, ainda existem ideologias retrógradas enraizadas, mesmo que de forma implícita, trazendo a ideia de um inimigo, traidor, que deve ser combatido sem piedade, a fim de que os "cidadãos de bem" desfrutem de plena paz.

A sede pela segurança social faz com que a severidade do tratamento dado ao inimigo não contemple a aplicação dos princípios e direitos constitucionais, propiciando a utilização e aplicação de fragmentos do Direito Penal do Inimigo.

A tese de Jakobs representa uma afronta as questões protetivas do ser humano, essencialmente quando nega a ele o seu status de pessoa, deixando de considerar a sua condição de ser humano.

No Brasil, embora a Constituição Federal de 1988 exija a observância dos princípios e das garantias fundamentais, buscando preservar a dignidade da pessoa humana, o ordenamento jurídico brasileiro possui fragmentos da tese do doutrinador alemão, ocasionando a punição de atos preparatórios, a incrementação da pena 
com base na periculosidade do agente, a destruição de aeronaves suspeitas que sobrevoarem o espaço aéreo brasileiro, dentre outros vestígios do Direito Penal do inimigo.

Sendo assim, pode-se concluir que é evidente a influência do Direito Penal do Inimigo, tornando-se uma grande tendência mundial de expansão, considerando o aumento da criminalidade.

\section{REFERÊNCIAS}

ALENCAR, Antônia Elúcia. A inaplicabilidade do direito penal do inimigo diante da principiologia constitucional democrática. Revista dos Tribunais. São Paulo, v. 99, n. 895, p. 471-498, Maio, 2010. Disponível em:

<https://www.revistadostribunais.com.br/maf/app/resultList/document?\&src=rl\&srguid =i0ad6adc60000016e432a1e8d2c4daa17\&docguid=Ifee242e0f25411dfab6f0100000 00000 \& hitguid=Ifee242e0f25411 dfab6f0 $10000000000 \&$ spos $=1$ \&epos $=1 \& \mathrm{td}=100 \& \mathrm{co}$ ntext=11\&crumb-action=append\&crumb-label=Documento\&isDocFG= true\&isFromMultiSumm=true\&startChunk=1\&endChunk=1>. Acesso em: 6 ago. 2019.

BUSATO, Paulo César. Regime disciplinar diferenciado como produto de um direito penal de inimigo. Revista de Estudos. Rio Grande do Sul, v. 4, n. 14, p. 137-145, Abr./Jun. 2004. Disponível em: <http://www.mundojuridico.adv.br>. Acesso em: 25 set. 2019.

CALLEGARI, André Luís; DUTRA, Fernanda Arruda. Direito penal do inimigo e direitos fundamentais. Revista dos Tribunais. São Paulo, n. 862, p. 429-442, Ago. 2007. Disponível em: https://www.revistadostribunais.com.br/maf/app/ resultList/document?\&src=rl\&srguid=i0ad82d9b0000016b86ac2adcdc5333a0\&docgu id=I5997af30f25111 dfab6f010000000000\& hitguid=I5997af30f25111 dfab6f01000000 $0000 \&$ spos $=1 \&$ epos $=1 \& \mathrm{td}=65 \&$ context $=42 \&$ crumb-action $=$ append \&crumblabel=Documento\&isDocFG=true\&isFromMultiSumm=true\&startChunk=1\&endChunk =1>. Acesso em: 24 Abr 2019 .

CONDE, Francisco Muñoz. De nuevo sobre el "derecho penal del enemigo". Buenos Aires: Hammurabi, 2005.

CONDE, Francisco Muñoz. As origens ideológicas do direito penal do inimigo.

Revista Brasileira de Ciências Criminais. São Paulo, n. 83, p. 95-119, Mar.-Abr. 2010. Disponível em: https://www.revistadostribunais.com.br/maf/ app/widgetshomepage/resultList/document\&src=rl\&srguid=i0ad82d9b0000016b66f8a a99dc508661\&docguid=107abbda0f 25211 dfab6f010000000000\&hitguid $=107$ abbda0f $25211 \mathrm{dfab} 6 \mathrm{f0} 10000000000 \&$ spos $=7 \&$ epos $=7 \& \mathrm{td}=110 \&$ context $=42 \&$ crumbaction $=a p$ pend\&crumblabel=Documento\&isDocFG=false\&isFromMultiSumm=true\&startChunk $=1 \&$ endChunk=1. Acesso em: 24 abr. 2019. 
COSTA, Fernanda Otero. Aquém da paz e além da guerra: uma análise jurídica e sociológica do direito penal do inimigo. Revista Brasileira de Ciências Criminais. São Paulo, n. 94, p. 57-85, jan./fev. 2012. Disponível em:

https://www.revistadostribunais.com.br/maf/app/resultList/document?\&src=rl\&srguid= i0ad6adc50000016b763da5398c1a57d5\&docguid=19cd35bc0465411e18a58000085

17971a\&hitguid=19cd35bc0465411e18a5800008517971a\&spos=2\&epos=2\&td=1173 \&context=48\&crumb-action=append\&crumb-label=Documento\&isDocFG= true\&isFromMultiSumm=true\&startChunk=1\&endChunk=1. Acesso em: 27 maio 2019.

GOMES, Luiz Flávio. Direito penal do inimigo (ou inimigos do direito penal).

Conteúdo Jurídico, Brasília-DF, nov. 20005. Disponível em:

$<$ http://conteudojuridico.com.br/consulta/Artigo/22193/direito-penal-do-inimigo-ouinimigos-do-direito-penal>. Acesso em: 6 nov. 2019.

GOMES, Luiz Flávio; MOLINA, Antonio García-Pablos de; BIANCHINI, Alice. Direito penal: introdução e princípios fundamentais. Vol. 1. São Paulo: Editora Revista dos Tribunais, 2007.

HOBBES, Thomas. Do cidadão. Trad. Renato Janine Ribeiro. São Paulo: Martins Fontes, 2002.

JAKOBS, Günther. Direito penal do inimigo. Org. de Luiz Moreira e Eugênio Pacelli de Oliveira. Trad. Gercélia Batista de Oliveira Mendes. Rio de Janeiro: Lumen Juris, 2008.

JAKOBS, Günther; MELIÁ, Manuel Cancio. Direito penal do inimigo: Noções e Críticas. Porto Alegre: Livraria do Advogado, Organização e Tradução: André Luís Callegari e Mereu José Giacomolli, 2005.

JAKOBS, Günther. MELIÀ, Manoel Cancio. Direito penal do inimigo: noções e críticas. Org. e trad. André Luis Callegari, Nereu Giacomolli. 4 ed. atual. e ampl. Porto Alegre: Livraria do Advogado, 2009.

JESUS, Damásio E. de. Direito penal do inimigo: breves considerações. Jus Navigandi, Teresina, ano 12, n. 1653, 10 jan. 2008. p. 1-5. Disponível em: <http://jus2.uol.com.br/doutrina/texto.asp?id=10836>. Acesso em: 09 jun. 2019.

MASSON, Cleber Rogério. O direito penal do inimigo. In: SILVA, Marco Antonio Marques da (coord.). Processo Penal e Garantias Constitucionais. São Paulo: Editora Quartier Latin do Brasil, 2006.

MÁRTÍN, Luis Gracia. O horizonte do finalismo e o direito penal do inimigo. Tradução Luiz Regis Prado e Érika Mendes de Carvalho. São Paulo: Editora Revista dos Tribunais, 2007.

MELIÁ, Cancio Manuel, JAKOBS, Günther. Direito penal do inimigo: Noções e Críticas. Tradução de: André Luís Callegari e Nereu José Giacomolli. Porto Alegre: Livraria do Advogado, 2005. 
MORAES, Alexandre Rocha Almeida de. Direito penal do inimigo: a terceira velocidade do Direito Penal. São Paulo: Editora Juruá, 2011.

NUCCI, Guilherme se Souza. Manual de direito penal: parte geral e parte especial. 7. ed. São Paulo: Revista dos Tribunais, 2011.

PRADO. Luiz Regis. Direito penal do inimigo. Carta Forense, 03 mar. 2009. Entrevista. Disponível em <http://www.cartaforense.com.br/conteudo/entrevistas/ direitopenal-do-inimigo/3624>. Acesso em 14 nov. 2018.

QUEIROZ, Paulo. Funções do direito penal: legitimação versus deslegitimação do direito penal. 3. ed. São Paulo: Editora Revista dos Tribunais, 2008.

RAZABONI JÚNIOR, Ricardo Bispo. Direito penal do inimigo e seu eco na sociedade brasileira: estudo de caso na fundação educacional do município de Assis. Revista do Laboratório de Estudos da Violência da UNESP, São Paulo, n. 19, Maio de 2017. Disponível em: http://revistas.marilia.unesp.br/index.php/levs/article/view/7014. Acesso em 14 ago. 2019.

SILVA, Lorena Ferreira; OLIVEIRA, Maria de Fátima; FOLLONE, Renata Aparecida. Direito penal do inimigo: uma crítica referente a sua aplicação. Diritto \& Diritti, v. 35610, 2011. Disponível em: <https://www.diritto.it/system/docs/35610/original/ direito-penal-do-inimigo.pdf>. Acesso em: 05 jun. 2019.

VALE, Ionilton Pereira. O direito penal do inimigo: fundamentos filosóficos e sistêmicos. Revista dos Tribunais. São Paulo, v. 100, n. 909, p. 165-186, jul. 2011. Disponível em: <https://bdjur.stj.jus.br/jspui/bitstream/2011/80558/ direito_penal_inimigo_vale.pdf>. Acesso em: 24 abr. 2019.

VÁSQUEZ, Manuel. El Ilamado derecho penal del enemigo. Especial referência ao derecho penal econômico. In: MELIÁ, Cancio; DÍEZ, Gómes-Jara (Orgs.). Derecho Penal de Enemigo: el discurso penal de la exclusión. Bueno Aires: Euros Editores, 2006. V. 1.

VELO, Joe Tennyson. O problema da fundamentação do direito penal do inimigo. Revista dos Tribunais. São Paulo, n. 894, p. 349-400, abr. 2010. Disponível em: https://www.revistadostribunais.com.br/maf/app/resultList/document?\&src=rl\&srguid= i0ad6adc50000016b766e609ef4cc95f6\&docguid=I7ee8c120f25111dfab6f010000000 000 \&hitguid=|7ee8c120f25111 dfab6f010000000000\&spos=1\&epos=1\&td=361\&cont ext=119\&crumb-action=append\&crumb-label=Documento\&isDocFG= true\&isFromMultiSumm=true\&startChunk=1\&endChunk=1. Acesso em: 27 mai 2019.

ZAFFARONI, Eugenio Raúl. O inimigo no direito penal. Tradução de Sérgio Lamarão. 2. ed. Rio de Janeiro: Revan, 2007.

Artigo recebido em: 11/10/2019

Artigo aceito em: 18/11/2019

Artigo publicado em: 16/12/2019 